\title{
A GEOGRAFIA DOS INVESTIMENTOS DIRETOS ESTRANGEIROS E DO COMÉRCIO INTERNACIONAL DO BRIC
}

\author{
THE GEOGRAPHY OF FOREIGN DIRECT INVESTMENTS AND \\ INTERNATIONAL TRADE OF THE BRIC \\ LA GEOGRAFÍA DE LAS INVERSIONES DIRECTAS EXTRANJERAS Y DEL \\ COMERCIO INTERNACIONAL DEL BRIC \\ Leandro Bruno Santos - Unesp - Presidente Prudente - Brasil \\ leandrobrunogeo@hotmail.com
}

\begin{abstract}
Resumo
0 objetivo deste artigo é compreender o processo de inserção externa das economias BRIC nos primeiros anos deste século, através da análise dos investimentos diretos estrangeiros e dos fluxos comerciais. Sob os auspícios da globalização, Brasil, Rússia, Índia e China promoveram uma maior integração internacional, intensificando os fluxos de investimento e de comércio com o resto do mundo. Assim, a análise é focada na atração e na promoção dos investimentos, bem como nas políticas de integração comercial. Os dados secundários foram obtidos da Organização Mundial do Comércio (OMC) e da Conferência das Nações Unidas para o Comércio e Desenvolvimento (UNCTAD).
\end{abstract}

Palavras-chave: Globalização. Fluxos comerciais. Investimentos diretos estrangeiros. BRIC.

\begin{abstract}
This paper aims to understand the external insertion process of the BRIC economies in the early years of this century, through the analysis of foreign direct investments and trade flows. Under the auspices of globalization, Brazil, Russia, India and China have promoted greater international integration by increasing investment flows and trade with the rest of the world. Thus, the analysis is focused on the promotion and attraction of investments, as well as on the policies of trade integration. Secondary data were obtained from World Trade Organization (WTO) and United Nations Conference on Trade and Development (UNCTAD).
\end{abstract}

Key words: Globalization. Trade flows. Foreign direct investments. BRIC.

\section{Resumen}

Se evalúa el proceso de inserción externa de las economías BRIC en los primeros años de este siglo, a través del análisis de las inversiones directas extranjeras y de los flujos comerciales. Brasil, Rusia, India y China siguieron las proposiciones de la globalización y promovieron una mayor integración internacional, intensificando los flujos de inversiones y de comercio con el mundo. Así, el análisis ha centrado en la atracción y promoción de las inversiones y en las políticas de integración comercial. Los datos secundarios se obtuvieron a partir de la Organización del Comercio Mundial (OMC) y de la Conferencia de las Naciones Unidas para el Comercio y Desarrollo (UNCTAD).

Palabras clave: Globalización. Flujos comerciales. Inversiones directas extranjeras. BRIC. 


\section{Introdução}

Os primeiros anos deste século estão sendo marcados pelo rápido crescimento dos "países-baleia", isto é, países com dimensões populacionais e continentais consideráveis, mercado interno integrado, estrutura econômica diversificada, Produto Interno Bruto (PIB) superior a US\$ 120 bilhões, Poder de Paridade de Compra (PPP) inferior a US\$ 18 mil, desigualdades sociais extremas etc. (DUPAS, 2006).

Dentre os "países-baleia” temos Brasil, China, Índia, Rússia etc. Em 2001, após a publicação do relatório Building Better Global Economic Brics, escrito pelo economista chefe do Goldman Sachs Jim O’Neill, o termo BRIC ${ }^{1}$ ganhou notoriedade e se tornou uma palavra da moda nos meios de comunicação. A principal ideia contida no relatório é que o BRIC (Brasil, Rússia, Índia e China) superará, em 2050, os seis países mais desenvolvidos (Estados Unidos, Japão, Alemanha, Inglaterra, França, Itália) em PIB.

A crise hipotecária estadunidense e as suas consequências nas demais economias desenvolvidas e subdesenvolvidas trouxeram à tona o termo BRIC com mais intensidade, desde finais de 2008, e com ele a proposição de que está acontecendo um descolamento/desligamento (decoupling) do BRIC em relação às economias mais desenvolvidas, ou seja, que de agora em diante esses quatro países serão a locomotiva do crescimento econômico mundial.

O principal propósito neste artigo é analisar o processo de inserção externa das economias BRIC nos fluxos de Investimentos Diretos Estrangeiros (IDE) e de comércio de bens e serviços nos primeiros anos deste século, a fim de demonstrar o grau de integração desse grupo de países no cenário internacional e de fortalecimento das relações materiais Sul-Sul.

\section{Os fluxos mundiais de IDE}

Desde os anos 1980, a UNCTAD tem publicado relatórios sobre o avanço de IDE, particularmente dos países desenvolvidos. Apesar da intensidade do fenômeno a partir de 1950, é inegável a existência de investimentos de empresas de países desenvolvidos e subdesenvolvidos em finais do século XIX. Enquanto processo, os IDE ganham prevalência a partir dos anos 1950 e 1960. 
Faz-se necessário distinguir IDE, investimentos em portfólios e novas formas de investimentos (NFI). Os IDE visam o controle acionário durável, sob a forma de aquisição, fusão, joint venture ou investimentos novos. Os investimentos em portfólios visam o rápido retorno (títulos públicos e privados). As NFI permitem que as Empresas Multinacionais (MN) controlem empresas em outros países prescindindo de capitais, por meio de acordos de licença, de assistência técnica, do franchising e da terceirização internacional (ANDREFF, 2000).

As diferentes formas de investimento se alteram temporal, setorial e espacialmente. Em finais do século XIX, prevaleciam os investimentos em portfólios, por meio de empréstimos entre governos (países desenvolvidos para subdesenvolvidos) e da implantação de infraestruturas em países subdesenvolvidos. É a partir de 1950, com o avanço internacional de empresas estadunidenses, europeias e japonesas, que a prevalência dos investimentos assume a forma de IDE. Desde os anos 1970, com o fim do padrão ouro-dólar e a adoção de medidas neoliberais de desregulamentação, as NFI têm se destacado.

Assim, em cada momento histórico, a mundialização do capital caracteriza-se por uma configuração - comercial, produtiva, financeira - que predomina sobre as demais, porém não as elimina. A dimensão que prevalece apresenta taxa de crescimento maior que as demais e retornos mais rentáveis (MICHALET, 2003). A mundialização, apesar de indissociável do capitalismo, não permance idêntica ao longo do tempo, devido às transformações em suas modalidades de existência.

As três formas de investimento estão concentradas na tríade (Estados Unidos, Europa e Japão) e em alguns países subdesenvolvidos, sendo que, dentro do Terceiro Mundo, as estratégias das MN deixam claro que existem aqueles no qual se investe, os NPI, e o resto que se deixa à ajuda pública para o desenvolvimento (ANDREFF, 2000, p. 33). Setorialmente, os IDE estão sendo redirecionados da indústria para o setor de serviços, pois os principais países investidores se tornaram economias de serviços (ANDREFF, 2000, p. 44).

Apesar da concentração dos investimentos na tríade, as políticas de atração de capitais, de desregulamentação, de ajuste macroeconômico, de privatização e a busca por novos mercados pelas EM resultaram em um maior direcionamento de IDE para países subdesenvolvidos (Gráfico 1). 


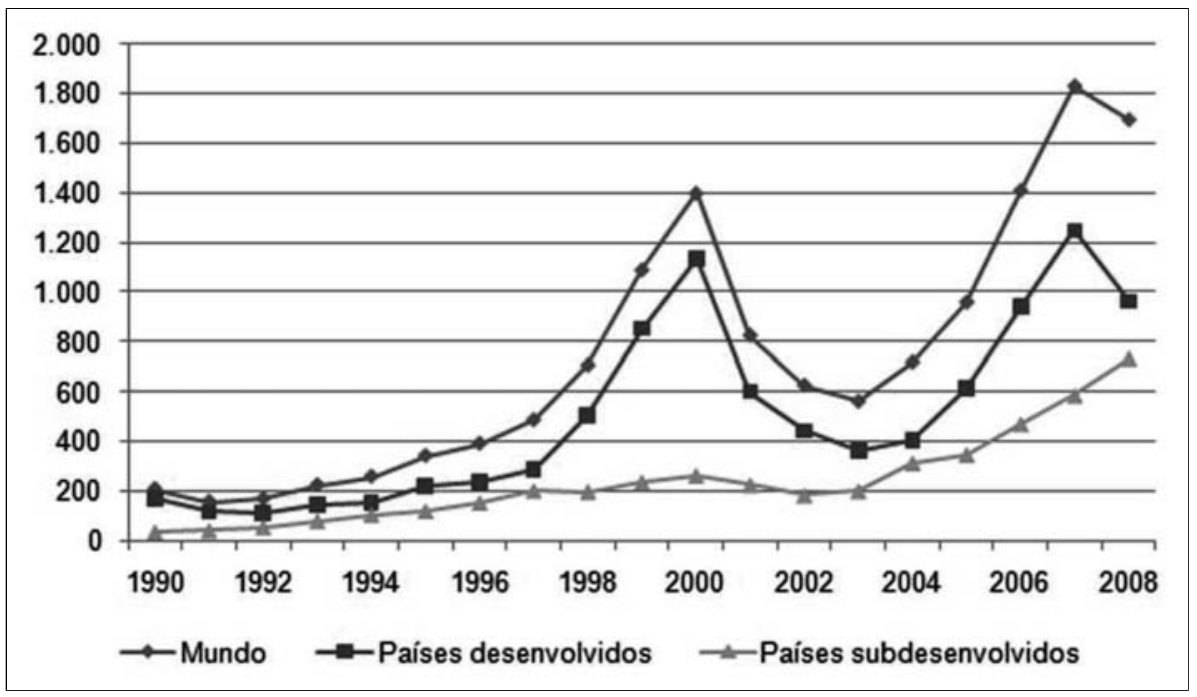

Gráfico 1: Recepção de IDE por grupo de países em US\$ bilhões (1990-2008).

Fonte: World Investment Report, 2008.

Org: Leandro Bruno Santos, 2009.

No começo dos anos 1990, os países subdesenvolvidos recebiam 17\% dos IDE mundiais e, ao final de 2008, a taxa se elevou para $43.3 \%$. Para Lacerda (2004, p. 266), 4 fatores explicam o aumento da participação dos países subdesenvolvidos no processo de globalização: a) o relativo sucesso de políticas públicas de estabilização em um cenário de ampla liquidez internacional; b) a intensificação de políticas de atração de capitais e das aberturas comercial e financeira; c) a ênfase nas políticas de privatização em muitos países; d) a crescente diversificação geográfica realizada pelas empresas multinacionais.

O aumento na participação enquanto espaços receptores de investimentos é acompanhado, paralelamente, pela concentração de capitais em alguns países. Ou seja, os espaços subdesenvolvidos se inserem desigualmente no processo de globalização, de modo que temos espaços da globalização e não a globalização do espaço (SANTOS, 2005). Outra ponto importante é que alguns países se inserem ativamente - regulando a entrada de capitais aos interesses nacionais - enquanto outros assumem uma postura passiva.

As economias BRIC são o destino de 45\% dos IDE enviados aos países subdesenvolvidos, recebendo US\$ 330 bilhões dos US $\$ 735$ bilhões. Em 
2008, à China (incluindo Hong Kong e Macau) foram destinados US\$173,2 bilhões, à Rússia, US\$ 70,3 bilhões, ao Brasil, US\$ 45 bilhões e à Índia, US\$ 41,5 bilhões. A China foi o destino 52,5\% dos investimentos despachados ao BRIC. Portanto, temos uma inserção assimétrica nos fluxos de investimentos tanto entre os países subdesenvolvidos como entre os países do BRIC (Mapa 1).

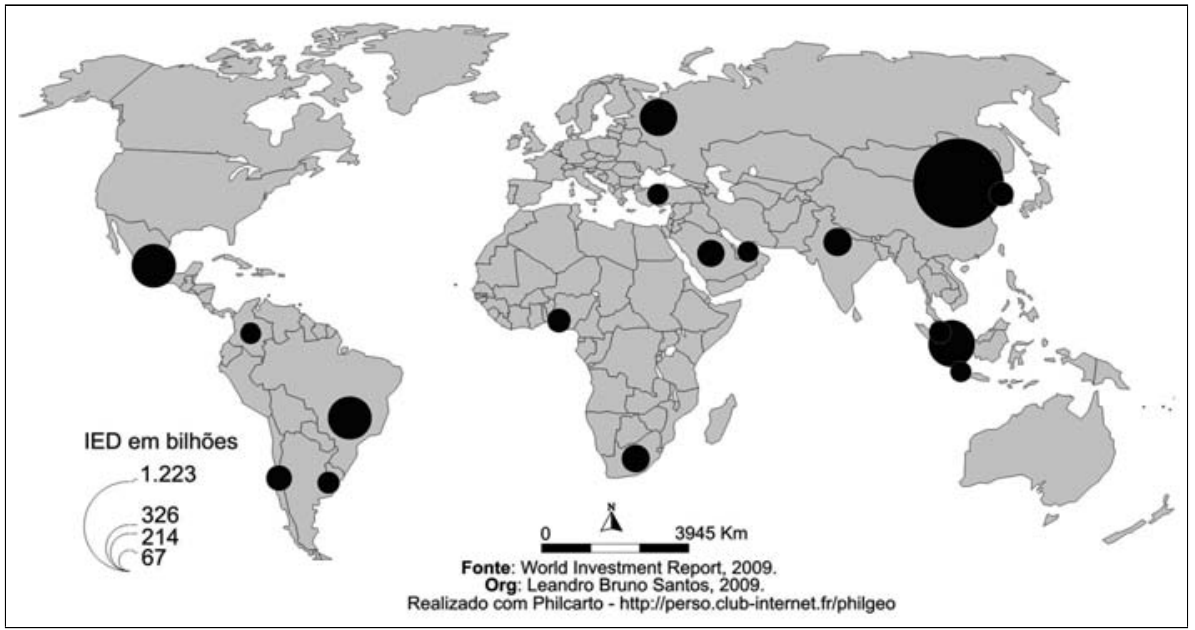

Mapa 1: Países subdesenvolvidos com maiores estoques de IDE em 2008.

O Mapa 1 demonstra que a distribuição espacial dos IDE direcionados aos países subdesenvolvidos é muito desigual, haja vista que a Ásia (China, Cingapura, Coreia do Sul, Turquia, Malásia, Índia, Indonésia e Emirados Árabes Unidos) recebeu US\$ 388,7 (52.9\%), a América Latina (Brasil, México, Chile e Argentina), US\$ 144,4 bilhões (19.6\%), Sul e Leste da Europa (Rússia), US\$ 114,3 bilhões (15.6), e África (África do Sul), US\$ 87,6 bilhões (11.9\%).

Quanto aos IDE realizados pelos países subdesenvolvidos, os números são menores que os recebidos, mas não menos importantes. No ínicio dos anos 1990, a periferia do sistema capitalista era responsável por apenas 5\% dos IDE mundiais, com US\$ 11 bilhões. Em 2000, atingiu 11.2\% (US $\$ 138$ bilhões) e, ao final de 2008, elevou a participação para 19\% (US\$ 351,2 bilhões) (Gráfico 2). 


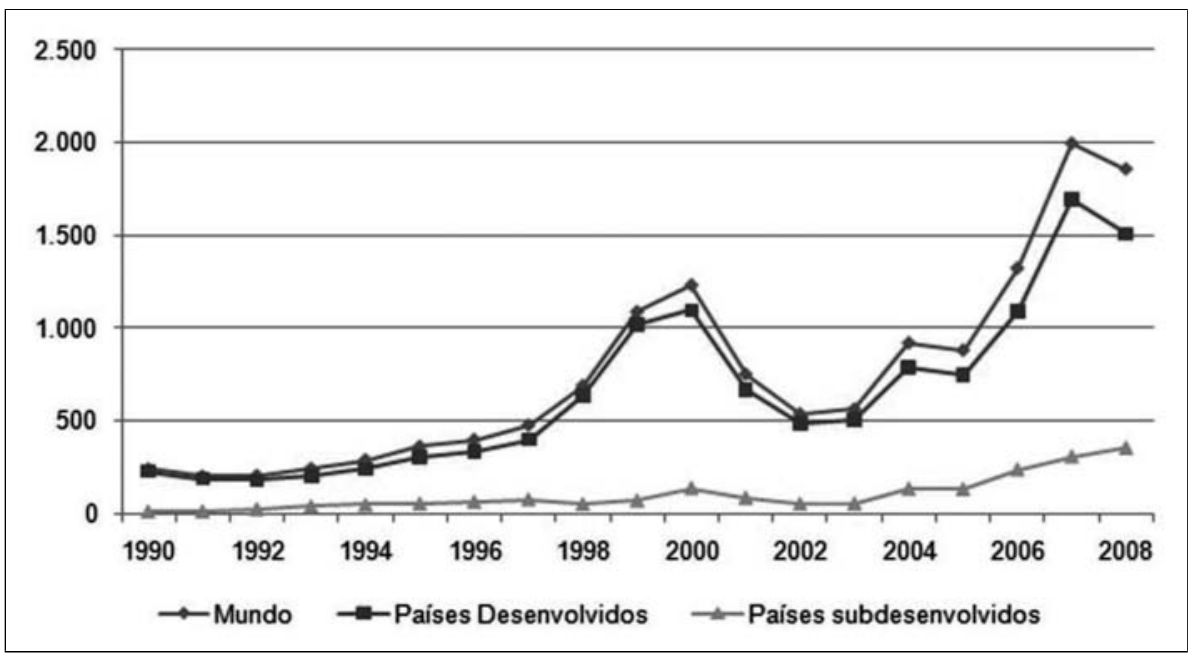

Gráfico 2: IDE realizados por grupo de países em US\$ bilhões (1990-2008).

Fonte: World Investment Report, 2008.

Org: Leandro Bruno Santos, 2009.

Se enquanto receptores IDE os países subdesenvolvidos têm mantido uma regularidade, enquanto investidores têm apresentado um rápido crescimento, apesar do percentual ser apenas a metade do de recepção. No entanto, o número de países subdesenvolvidos investidores é bem mais reduzido que o de receptores, sendo a maior parte deles os que foram integrados ao centro do sistema capitalista desde meados dos anos 1950 (SANTOS; SPOSITO, 2009).

Em 2008, as economias BRIC respoderam por 57.7\% de todos os IDE dos dos países subdesenvolvidos e por $10.7 \%$ do total mundial. A China concentrou a maior parte dos investimentos do BRIC, apresentando US\$ 112 bilhões (55.3\%). Rússia, Brasil e Índia respoderam por, respectivamente, US\$ 52,4 bilhões (25.9\%), US\$ 20,5 bilhões (10.1\%) e US\$ 17,7 bilhões (8.7\%).

Tanto na atração quanto na promoção de IDE, notamos que os países BRIC têm avançado significativamente desde os anos 1990, visando reduzir as assimetrias espaciais presentes no sistema interestatal. Essa inserção externa, porém, varia entre os países quanto aos papéis passivos (Brasil, Argentina, México, etc.) e ativos (China e Índia). 


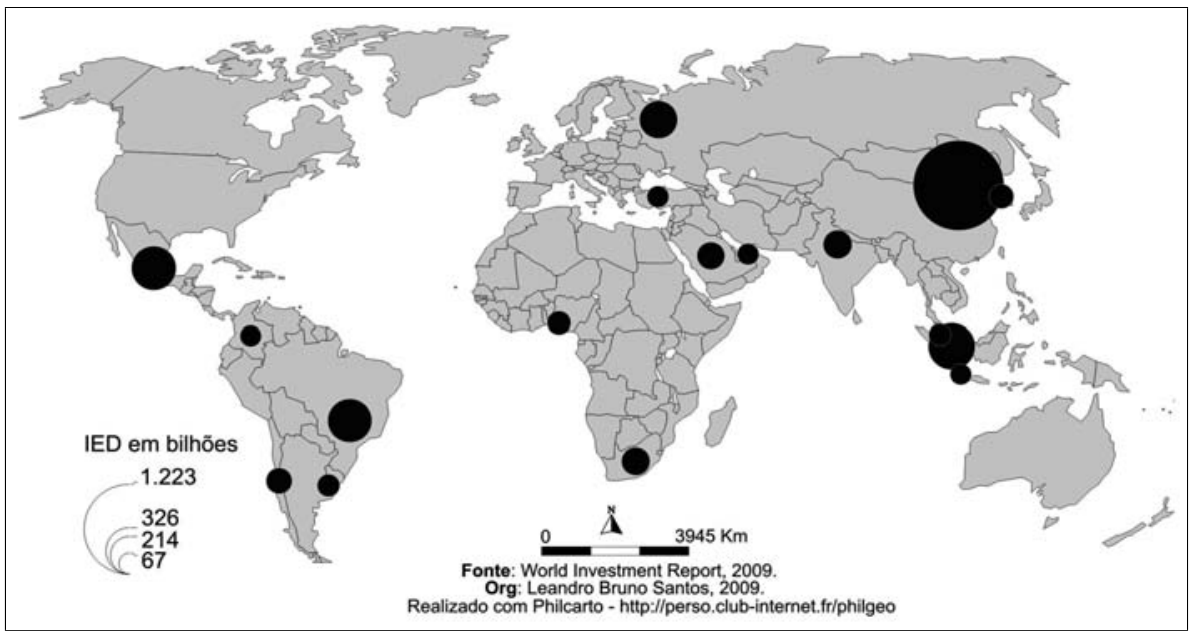

Mapa 2: Países subdesenvolvidos com principais estoques de IDE no exterior.

\section{As estratégias de atração e de promoção dos IDE}

Ao avaliarmos as estratégias de atração e de promoção de IDE, percebemos que os países estão fomentando a entrada e a saída de investimentos que visem aumentar as exportações e o grau de conteúdo tecnológico do parque industrial nacional. Existe, portanto, uma estratégia de desenvolvimento econômico e de redução das assimetrias nos fluxos mundiais entre os países.

Lacerda (2004) elabora um quadro com alguns países (Coreia, Taiwan, Malásia, China, Índia, Israel e Irlanda) e seus respectivos incentivos à entrada de IDE. Os benefícios incluem a isenção de impostos sobre a produçao e os lucros, sobretudo quando os IDE são direcionados às atividades intensivas em capital e tecnologia e às atividades mais atrasadas.

Em setores intensivos em tecnologia é importante o conhecimento das estratégias corporativas, o investimento em infraestrutura e a adoção de políticas fiscal e tributária atrativas. A inserção desigual entre os países em desenvolvimento é nítida ao observamos que a América Latina se integrou passivamente no processo de globalização, enquanto a Ásia articulou a abertura de mercado com alguns objetivos estratégicos (LACERDA, 2004).

Para Gonçalves (1999, p. 20), o problema central reside, de fato, nas estratégias e políticas de governos nacionais diante do capital estrangei- 
ro que, como todo capital, tem uma função objetiva simples: acumulação. Deste modo, são necessárias políticas que maximizem os benefícios da entrada de capitais, para que não haja a vulnerabilidade externa e a desnacionalização.

Enquanto na Ásia (principalmente China e Índia) o Estado não abdicou de seu papel no desenvolvimento e no controle do mercado, na América Latina, sobretudo o Brasil de Fernando Henrique Cardoso, a concentração econômica e a desnacionalização reduziram as possibilidades de maximizar os benefícios da entrada de IDE e transferiram para o exterior a tomada de decisões quanto a investimentos e a tecnologia (CARLEIAL, 2004; GONÇALVES, 1999).

Quando focalizamos a promoção de IED, notamos que os países subdesenvolvidos, particularmente as economias BRIC, estão se tornando importantes fontes de investimento no exterior. Esse processo não é recente e data de finais dos anos 1960. No passado esses IDE eram destinados aos países subdesenvolvidos, enquanto em anos mais recentes, tantos países subdesenvolvidos como desenvolvidos estão sendo visados por empresas do BRIC.

É relevante salientar que as estratégias espaciais das empresas, os setores selecionados para a expansão internacional e o papel do Estado são diferentes em cada uma das quatro economias. As empresas multinacionais brasileiras são intensivas em capital e recursos naturais, as chinesas intensivas em capital e tecnologia, as indianas com prevalência em serviços de outsourcing e de informação e as russas intensivas em recursos naturais (SAUVANT, 2005).

A multinacionalização de empresas do BRIC é um processo tanto espontâneo quanto incentivado. Índia e China estimulam o avanço de empresas no exterior, através de programas que fornecem empréstimos, relatórios sobre mercados promissores para expansão, etc. No Brasil, há um tímido programa do Banco Nacional de Desenvolvimento Econômico e Social (BNDES) que estuda as propostas de investimento das empresas brasileiras, empresta capitais e exige, como contrapartida, exportações em igual valor durante um determinado tempo.

Portanto, nem todos os países adotaram políticas e estratégias de promoção e atração de capitais visando o desenvolvimento econômico e tecnológico, o aumento das exportações e de empregos, etc. China e Índia, por exemplo, promoveram uma inserção ativa no processo de globalização, com o fito de extrair os benefícios da integração aos fluxos mundiais de capitais. 


\section{Fluxos mundiais de comércio}

Nos últimos 10 anos, as exportações mundiais cresceram quase 3 vezes, elevando-se de US\$ 5.5 para US\$ 16.1 trilhões, graças à maior abertura econômica promovida pelos países, à intensificação das trocas internacionais intra-firmas, à entrada da China como membro permanente da OMC, ao aumento dos acordos bilaterais, à intensificação das trocas no âmbito dos blocos comerciais, entre outros.

O significativo aumento das trocas contrasta, porém, com a elevada concentração das exportações em poucos países (Tabela 1), principalmente os desenvolvidos, o que demonstra que, apesar do aumento das trocas, países desenvolvidos e subdesenvolvidos se inserem de maneira muito desigual.

Tabela 1: Principais exportadores mundiais em 2008, em US\$ bilhões.

\begin{tabular}{clcc}
\hline Ranking & \multicolumn{1}{c}{ Países } & Exportações & \% \\
\hline 1 & Alemanha & 1.465 & 9.0 \\
2 & China & 1.428 & 8.8 \\
3 & Estados Unidos & 1.300 & 8.0 \\
4 & Japão & 782 & 4.8 \\
5 & Holanda & 634 & 3.9 \\
6 & França & 608 & 3.8 \\
7 & Itália & 539 & 3.3 \\
8 & Bélgica & 477 & 3.0 \\
9 & Reino Unido & 458 & 2.8 \\
10 & Canadá & 456 & 2.8 \\
\hline
\end{tabular}

Fonte: www.wto.org/english/news.

Org: Leandro Bruno Santos, 2009.

Os dados mostram que os 10 principais países exportadores controlam mais de $50 \%$ das vendas mundiais e que a China é o único país subdesenvolvido a fazer parte do grupo. Eles demonstram ainda que, apesar da prevalência dos países da tríade, a forte entrada da China trouxe novos elementos para interpretar e mapear os fluxos mundiais. Atualmente, cerca de 1/3 das exportações chinesas são destinadas às principais economias mundiais (Estados Unidos, Japão e Alemanha), de modo que, em vez de triádico, o comércio caminha para ser quadrático. 
O Brasil, embora tenha quadruplicado suas exportações, detém parcela inexpressiva das vendas internacionais, com $1 \%$. Isso resulta, historicamente, da própria estratégia de industrialização por substituição das importações baseada na proteção do mercado doméstico e na dinâmica de acumulação voltada às condições internas. Países e cidades-estado na Ásia (Coréia do Sul, Malásia e Cingapura), cuja industrialização baseouse na exportação, apresentam alta integração ao comércio internacional (SANTOS, 2008).

A propósito dos principais importadores mundiais, a lista dos 10 países não muda. Nos últimos 10 anos, as importações mundiais triplicaram, elevando-se de US\$ 5.6 para US\$ 16.4 trilhões. Os 10 principais países importadores somaram mais de $52 \%$ de todas as compras externas (Tabela 2).

Tabela 2: Principais importadores mundiais em 2008, em US\$ bilhões.

\begin{tabular}{cccc}
\hline Ranking & Países & Importações & \% \\
\hline 1 & Estados Unidos & 2.166 & 13.2 \\
2 & Alemanha & 1.206 & 7.3 \\
3 & China & 1.133 & 6.9 \\
4 & Japão & 762 & 4.6 \\
5 & França & 707 & 4.3 \\
6 & Reino Unido & 632 & 3.8 \\
7 & Holanda & 574 & 3.5 \\
8 & Itália & 556 & 3.4 \\
9 & Bélgica & 470 & 2.9 \\
10 & Canadá & 418 & 2.5 \\
\hline
\end{tabular}

Fonte: www.wto.org/english/news.

Org: Leandro Bruno Santos, 2009.

Grande parte das importações mundiais está concentrada nos Estados Unidos, nos Países Europeus, na China e no Japão. Cerca de 1/4 das importações chinesas são provenientes dos Estados Unidos, da Alemanha e do Japão, o que demonstra que a China não só exporta como também importa das três principais economias mundiais quantidades expressivas de mercadorias e serviços. O Mapa 3 mostra, claramente, a forte ligação entre América do Norte, Europa e Ásia, bem como a participação tímida da África, América Central e do Sul e Comunidade dos Estados Independentes (CEI) nas trocas de mercadorias em escala mundial. 


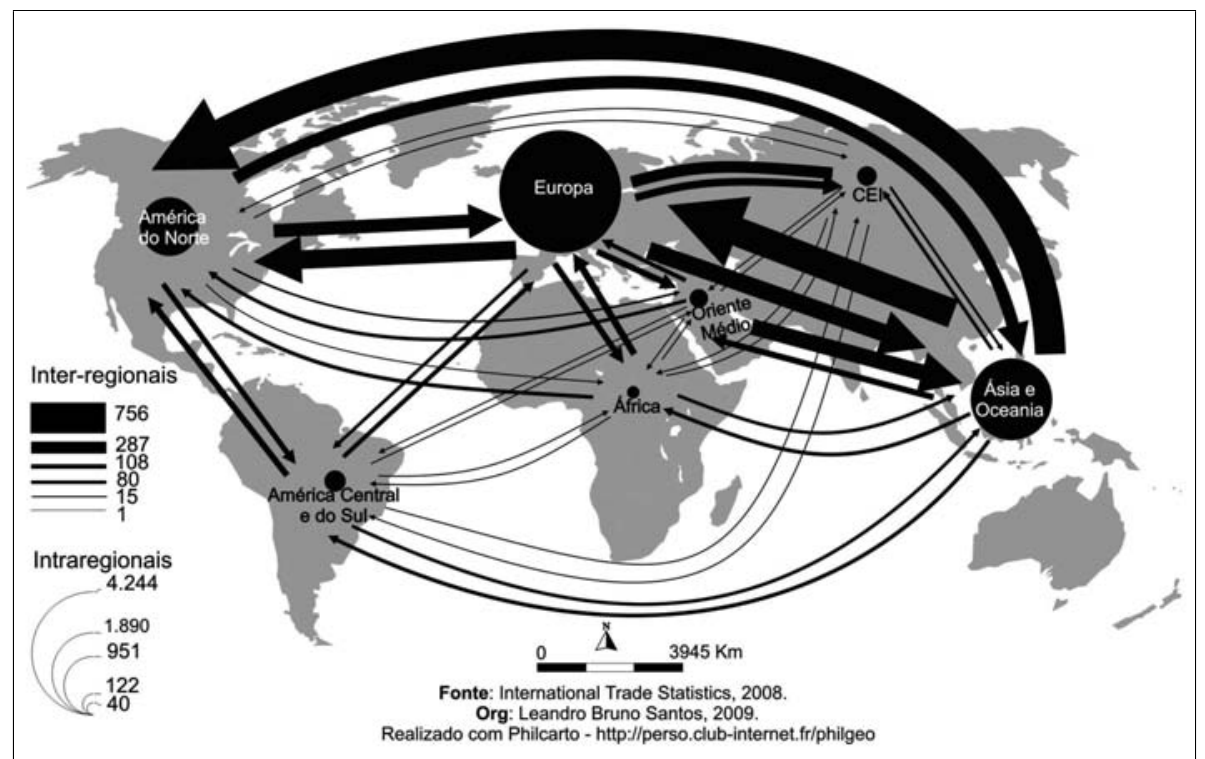

Mapa 3: Comércio de mercadorias no mundo, em US\$ bilhões, em $2007 .^{2}$

Outro aspecto digno de nota no mapa 3 é o comércio intrarregional, em que Europa, Ásia e América do Norte, respectivamente, apresentam forte integração comercial. Sem dúvida, o fortalecimento do comercial regional resulta do fortalecimento dos blocos comerciais, como NAFTA (Acordo de Livre Comércio da América do Norte), UE (União Européia) e ASEAN (Associação de Nações do Sudeste Asiático).

Nos primeiro anos deste século, ao países do BRIC duplicaram suas exportações, atingindo $14 \%$ do total mundial. É em função desse rápido avanço que os meios de comunicação e revistas especializadas têm destacado que esses países desempenharão importante papel num futuro próximo. Em 2008, a China exportou US\$ 1,4 trilhão, a Rússia, US\$ 471 bilhões, o Brasil, US\$ 197 bilhões, e a Índia, US\$ 179 bilhões. Só a China foi reponsável por 62\% de todas as exportações do BRIC, a Rússia, 21\%, o Brasil, 9\%, e a Índia, 8\%.

Quanto às importações os países BRIC quintuplicaram suas compras entre 2000 e 2008, com o aumento de US\$ 380 bilhões para US\$ 1,9 trilhão. Em termos percentuais, a participação do BRIC elevou-se de 6\% para 12\%. Em 2008, só a China, importou US\$ 1,133 trilhão (60\%), a Rússia, US\$ 292 bilhões (15\%), a Índia, US4 291 bilhões (15\%), e o Brasil, US\$ 182 bilhões (10\%). 
Portanto, as assimetrias nas relações de trocas estão presentes nas diversas escalas geográficas. Não só em escala mundial, mas também entre os países do BRIC, a inserção comercial é extremamente desigual. As relações bilaterais entre Brasil, Rússia, Índia e China não fogem à regra (Mapa 4).

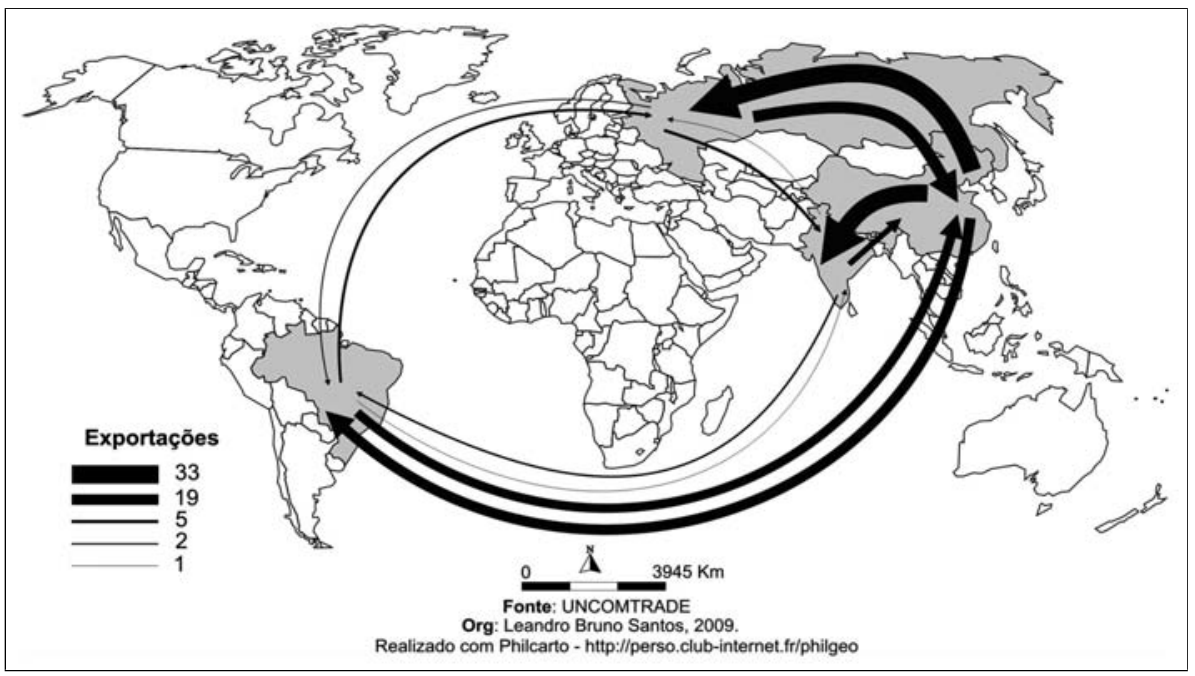

Mapa 4: Comércio entre os membros do BRIC, em 2008, em US\$ bilhões.

Brasil, Rússia e Índia ampliaram substancialmente suas relações comerciais com a China, que se tornou um importante destino para suas exportações. Por exemplo, mais de $8 \%$ das exportações brasileiras tiveram como destino o mercado chinês, enquanto os demais apresentaram taxas de $5 \%$. Portanto, os membros do BRIC são mais dependentes da China do que esta deles, uma vez que o principal mercado para exportações do grupo para a China - russo - correspondeu a apenas $2.3 \%$ de suas exportações.

Se a China for desconsiderada, os dados de importação e exportação entre os demais membros do BRIC são muito pequenos com relação aos valores totais de suas trocas. A China é, pois, no aspecto econômico, quem dá sentido e dinamismo ao grupo. Quando se leva em consideração a importância política e geopolítica, Brasil, Rússia e Índia ganham relevância e fortalecem o grupo nos fóruns econômicos mundiais e nas organizações multilaterais. 
Por trás desse avanço da China no cenário internacional e do discurso de que é um modelo para os demais países subdesenvolvidos é importante perceber que novas relações de dependência e de trocas desiguais têm surgido, haja vista que as exportações do BRIC à China são, sobretudo, de grãos, de minérios e de recursos energéticos. Essas matérias-primas, inclusive, já estão sendo adquiridas mediante a expansão de empresas chinesas na África e na América Latina.

\section{Considerações finais}

Esse texto permitiu compreender os fluxos mundiais de investimento e de bens nas diversas escalas. Apesar da concentração dos fluxos nos países desenvolvidos, notamos que os países BRIC - principalmente a China - estão aumentando a intensidade de inserção na economia mundial. A maior integração internacional, porém, longe de reduzir as desigualdades materiais entre os países, é marcada por novas assimetrias e novas relações de dependência.

Todavia, a importância assumida pelo BRIC nos fluxos mundiais traz também maiores possibilidades de diminuição da submissão aos interesses e pressões dos países desenvolvidos. As ligações materiais entre os países do Sul abrem novas perspectivas para o fortalecimento Sul-Sul e a relativização Norte-Sul, quanto às compras de títulos de países do próprio $\mathrm{Sul}^{3} \mathrm{e}$ dminuição dos poderes de imposição de instituições multilaterais, ao aumento do poder de barganha nas rodadas comerciais etc. Tudo isso, porém, dependerá das escolhas políticas e econômicas de Brasil, Rússia, Índia e China, sobretudo deste último.

\section{Notas}

1 Este termo representa não só as letras iniciais de Brasil, Rússia, Índia e China, como também significa "bloco" ou "tijolo" na língua inglesa.

2 Os dados de 2008, por regiões, ainda não foram disponibilizados pela UNCTAD. Para fins de compreensão dos fluxos comerciais mundiais, fez-se necessário utilizar o relatório de 2007, que não compromete o objetivo de destacar a concentração das trocas.

3 Recentemente, a Venezuela tornou-se o maior detentor de títulos da dívida externa argentina. 


\section{Referências}

ANDREFF, Wladimir. Multinacionais globais. Bauru: EDUSC, 2000.

CARLEIAL, Liana M. F. Subdesenvolvimento globalizado: A resultante das escolhas da política econômica brasileira dos anos noventa. Revista paranaense de desenvolvimento, Curitiba, n.106, p. 7-28, jan./jul. 2004.

CHESNAIS, François. A mundialização do capital. São Paulo: Xamã, 1996.

DUPAS, Gilberto. África do Sul, Brasil e Índia: Divergências, convergências e perspectivas de alianças. In. Índia, Brasil e África do Sul: Perspectivas e alianças VILLARES, Fabio (Org.). São Paulo: Editora UNESP: IEEI, 2006.

GONÇALVES, Reinaldo. Globalização e desnacionalização. São Paulo: Paz e Terra, 1999.

LACERDA, Antônio C. Inserção externa dos países em desenvolvimento: Uma análise dos fluxos de investimentos diretos estrangeiros e exportações, Revista de Economia Contemporânea, n. 8, p. 263-282, Rio de Janeiro, jul/dez. 2004.

MICHALET, Charles-Albert. O que é a mundialização? São Paulo: Loyola, 2003.

SANTOS, Milton. Da totalidade ao lugar. São Paulo: Edusp, 2005.

SANTOS, Leandro B. As diferentes trajetórias dos países de industrialização tardia asiáticos e latino-americanos, Caderno Prudentino de Geografia, n. 30, p. 71-98, Presidente Prudente, 2008.

SANTOS, Leandro B.; SPOSITO, Eliseu S. Considerações geográficas sobre alguns aspectos recentes do BRIC. Presidente Prudente, 2009 (no prelo).

SAUVANT, Karl P. New sources of FDI: The BRICS. Outward FDI from Brazil, Russia, India and China. The Journal of world investment \& trade, p. 339 - 709, 2005.

UNCTAD. World Investment Report. Transnational corporations and the infrastructure challenge. United Nations: New York, 2008.

WILSON, Dominic; ROOPA, Purushothaman. Dreaming with BRICs: The path to 2050. Global Economics Paper, n. 99, October 2003.

Leandro Bruno Santos - Doutorando em Geografia pela Universidade Estadual Paulista. 